\title{
Презентация комплексного проекта (ПКП) кооперативного социального предпринимательства (КСП) \\ В.П. Щербина
}

ПКП КСП - это аннотация краткой презентации комплексного проекта (КПКП) КСП + КПКП + приложение: (пояснения, дополнения) к КПКП + справочная информация

\section{Аннотация}

Представлен проект международного долговременного надежного коллективного предпринимательства. Таким оно может быть, по мнению автора, только в виде, так называемого, кооперативного социального предпринимательства (КСП). Автор обосновывает, почему и в чем система КСП будет иметь преимущества, а также то, что, практически, с самого начала она проектируется, и будет создаваться, как международная система (МС). Преимущества МС КСП будут реализовываться в бизнес-проектах, которые постепенно будут трансформироваться в международные мегапроекты и служить экономической основой МС КСП, включая национальные и региональные системы КСП.

\section{Содержание}

(Названия разделов, пунктов и № страниц, где они находятся в данной Презентации)

\begin{tabular}{|c|c|c|}
\hline $\begin{array}{l}\text { № } \\
\text { п/п }\end{array}$ & Вопросы & Стр \\
\hline 1 & Принятые обозначения & 2 \\
\hline 2 & Краткая презентация комплексного проекта (КПКП) КСП & 2 \\
\hline 3 & $\begin{array}{l}\text { Кому (т.е. каким людям) комплексный проект особенно интересен, почему } \\
\text { (и чем)? }\end{array}$ & 3 \\
\hline 4 & $\begin{array}{l}\text { Важные качества и преимущества системы КСП } \\
\text { (по сравнению с частными и государственными организациями) }\end{array}$ & 4 \\
\hline 5 & $\begin{array}{l}\text { Финансовая основа для прибыльности, внедрения, выживания и развития } \\
\text { системы КСП (СКСП) }\end{array}$ & 4 \\
\hline 6 & Вознаграждения участникам КСП & 5 \\
\hline 7 & Особый порядок вознаграждения участникам на начальный период внедрения КП & 5 \\
\hline 8 & $\begin{array}{l}\text { Направления развития КСП (резервы роста для молодых участников и } \\
\text { возможности для участников КСП, а в будущем и не только для участников) }\end{array}$ & 6 \\
\hline 9 & С чего начинать работу по созданию КСП & 8 \\
\hline 10 & Приложение (пояснения, дополнения) к КПКП & 9 \\
\hline 11 & Некоторые наиболее важные замечания о первоочередных шагах внедрения КП & 9 \\
\hline 12 & $\begin{array}{l}\text { О важности общественной организации (ОО) взаимопомощи граждан (ВПГ) } \\
\text { в концепции КСП и КП }\end{array}$ & 9 \\
\hline 13 & $\begin{array}{l}\text { О значении СКСП и МС КСП для фактически одиноких людей и для тех, } \\
\text { кому маячит такое одиночество в будущем }\end{array}$ & 10 \\
\hline 14 & $\begin{array}{l}\text { Последовательность шагов по созданию общественной организации (ОО) } \\
\text { взаимопомощи граждан (ВПГ). Некоторые элементы организационной } \\
\text { структуры ООВПГ (как они представляются автором) }\end{array}$ & 11 \\
\hline 15 & $\begin{array}{l}\text { Дополнительно о необходимой работе по созданию общественной организации } \\
\text { взаимопомощи граждан и, вообще, что обязательно нужно сделать в начальный } \\
\text { период создания КСП }\end{array}$ & 12 \\
\hline 16 & Краткая история работы над проектом & 14 \\
\hline 17 & Будущее МС КСП & 14 \\
\hline 18 & Справочная информация & 14 \\
\hline
\end{tabular}




\begin{tabular}{|l|l|l|}
\hline 19 & Общепринятые сокращения & 14 \\
\hline 20 & Краткая справка по наследованию & 14 \\
\hline 21 & Тройская унция & 15 \\
\hline
\end{tabular}

\section{Принятые обозначения}

Общепринятые сокращения см. одноименный пункт в Приложении, в подразделе: «Справочная информация».

БП - бизнес-проект

КП - комплексный проект

КСП - кооперативное социальное предпринимательство, то же, что и ОИП общественное инновационное предпринимательство /1/, в работах, заметках, презентациях до 2014г.

СКСП - система кооперативного социального предпринимательства.

ЧБ - частный бизнес.

ИПСМО - информационно-посредническая система по медицинскому обслуживанию, МИПСМО - международная ИПСМО.

KTK - консалтингово-трастовая компания, MKTK - международная (KTK).

\section{Краткая презентация комплексного проекта (КПКП) кооперативного социального предпринимательства КСП}

КПКП - это первый вариант краткой презентации версии комплексного проекта (КП), разрабатываемой с 2017г. (немного подробнее см. в приложении данной презентации пункт с названием «Краткая история работы над проектом»). КПКП может быть основой очень краткого изложения сути комплексного проекта (КП) участниками, иначе говоря, основой для «презентации» КП на «бегу» (или на ходу). КСП - это кооперативное (точнее скооперированное) социальное предпринимательство, это не кооператив в обычном понимании этого термина, т.е. не обычный производственный кооператив. Это кооперативное социально инновационное образование (в развитом состоянии международное и даже глобальное) - добровольное объединение необычных социальных предпринимателей (СП). Необычных СП в том смысле, что это в большинстве своём, по мнению автора, будут СП не альтруисты, а прагматики. А КСП это тоже не обычная благотворительная система. Она будет творить благо в первую очередь для своих участников с учетом их вклада в систему КСП, а сверх их вклада и для небогатых клиентов на хозрасчетной основе. А для остальных, т.е. богатых людей, КСП будет оказывать услуги (как правило, это дорогие и очень дорогие услуги), как бизнес объединение. Так что КСП это гибрид социального предпринимательства с подчиненным ему бизнесом. Востребованность КСП связана с его эксклюзивными качествами (см дальше).

Предлагаемый проект, по мнению автора, наверно, единственный реальный шанс для многих молодых людей (да и не только молодых) достичь в перспективе, возможно, лучшего мирового уровня обеспеченной жизни (особенно, в отношении медицинского и социального обеспечения (в старости и в случае тяжелой болезни или инвалидности) для себя и своих близких). А также достичь творческих успехов, признания своих заслуг и вклада, и сохранение этого вклада на личном страховом счете в международном общественном страховом фонде в международной системе КСП. Причём часть этого вклада по желанию участника будет выплачиваться в виде денежного вознаграждения.

Примечание. Вообще, все конкретные предложения в данной презентации (даже без вероятностных оговорок типа: может быть, возможно, скорее всего, и т.п.) это видение автора в качестве возможного, по мнению автора, варианта. Они даны в качестве примера 
для лучшего понимания проекта и пути его реализации. Скорее всего, участники для почти всех подобных предложений с помощью экспертов в процессе внедрения КП найдут лучшие варианты их реализации, модифицируя предложенный автором вариант или находя новые.

Так как внедрение этого проекта, по мнению автора, в виде одного даже локального бизнес-проекта (БП), весьма вероятно, приведет к реализации других проектов в рамках всего комплексного проекта. Что, скорее всего, послужит началом последующей реализации целой системы (пакета) международных мегапроектов в одной глобальной (т.е. международной) системе КСП, так как её стремление к максимальной глобальности структурно и экономически обусловлено. Потому как в таком состоянии МС КСП наиболее эффективна и рентабельна, что подкрепляется другими ее преимуществами. См. ниже пункт: «Важные качества и преимущества системы КСП (по сравнению с частными и государственными организациями)».

Кому (т.е. каким людям) комплексный проект особенно интересен, почему (и чем)?

1.1. Молодым добросовестным людям (особенно, творчески и организационно амбициозным, но таких мало, поэтому и амбициозным прагматикам), которые хотят быть востребованы (не быть изгоями, незваными гостями) на Западе. Быть одними из активных (даже, может быть, ключевых) участников проекта, если, конечно, они сами захотят и для этого будут предпосылки, способности.

1.2. Тем людям, особенно, кто обладает хотя бы небольшими организационнокоммуникационными способностями, и кто имеет близкого человека, которому понадобится длительное лечение в другом городе, Москве, а может даже в зарубежном медицинском центре (не сейчас, так в будущем, это может понадобиться любому). Для создания такой международной информационно-посреднической медицинской системы обслуживания больше всего подходит система КСП (и это один из мегапроектов КП).

1.3. Фактически одиноким людям или тем, кому маячит такое одиночество в будущем (что тоже может случиться у большинства людей). Под фактически одиноким подразумевается человек, у которого нет такого близкого человека, (не обязательно родственника), проживающего в том же городе (родственник есть, например, но он живет в другом городе и не сможет в любой момент так просто приезжать и жить какое-то время в одной квартире или где-то рядом). Нет близкого человека, который сможет оказывать достаточно продолжительную (не разовую) помощь, даже не связанную с уходом, а просто информационно-посредническую, например, в решении каких-либо вопросов, и даже выполнит определенные действия после смерти. По мнению автора, фактически одинокими в пожилом возрасте в недалеком будущем будет большинство людей. Поэтому тем из таких людей, которые чувствуют у себя наличие определенных возможностей (а именно, организационных и временных (т.е. свободного времени)), стоит начинать со средних лет (особенно, незамужним женщинам после 35 лет, но и несемейным мужчинам тоже) интересоваться возможностью своего участия в КП. А пока КП не начал внедряться, то искать, кому может быть интересен проект среди своих знакомых не только близкого возраста, но и молодых и энергичных пожилых людей. Тем самым вы, возможно, сами станете инициатором запуска КП. Но в любом случае это будет ваш вклад в будущее внедрение проекта, который запомнится другими будущими участниками КП, которых вы заинтересуете проектом. Кроме того, за счет увеличения числа своих знакомых, с которыми вы ближе познакомитесь и тем самым, возможно, решите проблему создания собственной семьи (не сейчас, так в недалеком будущем).

Со временем фактически одиноких и тех, кому понадобится специальное лечение, будет всё больше. Это будет происходить в силу старения населения, уменьшения количества детей в семье (наверно, до уровня западноевропейских стран), а также в связи с 
др. причинами во всех более и менее развитых странах.

Даже если участник КП КСП не заработает большого вклада в КП, он приобщится к международной системе (МС) КСП, которая, по мнению автора, со временем станет глобальной, с множеством направлений развития и большим спектром оказываемых услуг, и огромной по численности участников. Так что, если автор (которому уже 70 лет), наверно, не доживет до этого времени, то молодые люди, когда они станут пожилыми (и даже раньше), смогут получить от МС КСП всестороннюю поддержку. Хотя те люди, кто внесет даже несущественный и эпизодический вклад, но вначале внедрения КП тоже получат вознаграждение (подробнее см. далее по тексту КПКП пункт «Особый порядок вознаграждения участникам КП на начальный период внедрения КП»).

\section{Важные качества и преимущества системы КСП \\ (по сравнению с частными и государственными организациями)}

1. Надежность системы КСП обеспечивается тем, что в ней будет постоянно осуществляться нравственный отбор (т.е. отбор добросовестных), а среди них уже по профессиональным качествам (и образованию), особенно на руководящие посты и постоянный внутрисистемный качественный контроль. Будет проводиться систематическая и регулярная дополнительная профессиональная подготовка, практически всех работников.

Отбор самых лучших (т.е. добросовестных) участников будет обеспечивать принятие и осуществление максимально справедливых решений в разных спорах и ситуациях, и при возникновении непредвиденных обстоятельств.

2. Неограниченное время развития этой системы обусловлено постоянным пополнением участников, и связано с неограниченным ничем приемом новых участников и инновационным характером системы. И, пожалуй, даже это самая главная основа неограниченного времени развития системы КСП - преимущество этических запросов (потребностей) участников КСП перед экономическими выгодами.

3. Международный характер системы связан с международной основой системы КСП, а именно, с международной общественной организацией, и выгодой экономического сотрудничества между региональными, и особенно между национальными системами КСП, а также их бизнес-партнерства с международными компаниями МС КСП.

4. Наконец, преимущества системы заложены в возможности реализации пакета международных мегапроектов в одной глобальной (т.е. международной) системе КСП, так как её стремление к максимальной глобальности структурно и экономически обусловлено. Потому как в таком состоянии система (МС КСП) наиболее устойчива, эффективна и рентабельна.

Финансовая основа для прибыльности, внедрения, выживания и развития системы КСП (СКСП)

Интерес со стороны инвесторов (крупных собственников бизнеса) обусловлена п.п. 1 и 2 предыдущего подраздела, а также тем, что основная часть (участников фактически одиноких людей) будет находиться примерно в том же положении, что и инвесторы, с точки зрения своих интересов. А именно, они заинтересованы в первую очередь не уровнем прибыльности системы, а в надежном и длительном исполнении завещаний, честности менеджмента системы (привлечении лучших экспертов для оценки ситуации и принятия лучших решений). И создании особо надежной, честной и долговечной консалтинго-трастовой компании (KTK), которая будет в будущем надежно и точно исполнять их завещания, помогая наследникам-родственникам управлять их бизнесом, а в случае необходимости КСК будет временно, а может быть и неограниченное время управлять их бизнесом. В СМИ появлялись сообщения о высказываниях некоторых миллиардеров о том, что детям 
необходимо оставлять в качестве наследства не больше миллиона долларов, иначе они будут демотивированы, а бизнес угроблен. Кроме того, некоторые крупные инвесторы (банкиры, собственники крупных страховых, частных пенсионных компаний и других компаний) будут заинтересованы в реализации и других направлений совместно с СКСП (в силу эксклюзивных свойств СКСП). Так как лучшей основы диверсификации и сохранении части их бизнеса нет. А в будущем при развитой СКСП почти собственники успешного бизнеса будут заключать договора завещания с СКСП. Она будет сохранять, и развивать их бизнес (и финансировать наследников), как пожелает завещатель, т.е. собственник бизнеса.

\section{Вознаграждения участникам КСП}

Планируется, что все участники КП будут получать вознаграждения соответствующие их вкладу. Участники БП начнут получать вознаграждения по частям, как начнут приносить чистую прибыль БП, в которых они участвуют. Чистая прибыль будет образовываться от того, что основными клиентами будут богатые люди (не участники КСП). О выделенном тексте см. Примечание в конце данной презентации. Они будут платить, по рыночным ценам соответствующих услуг, как в частном предпринимательстве. А участники КСП будут платить за услуги системы КСП по ценам, обеспечивающим рентабельность, т.е. себестоимость обслуживания без накруток. Отсюда и возможность развития и оплата вознаграждений, компенсация затрат участникам КСП за счет обслуживания в основном богатых клиентов, а небогатые должны стать участниками КСП, чтобы им были доступны необходимые и, высококачественные услуги (но, конечно, без роскоши как для богатых).

Предполагается, что информация о вкладе каждого участника будет сохраняться в виде подробного описания работы, временных затрат и т.п. Например, участие в работе общественной организации, группы (какой), органа координации, управления (какого), когда (дата), сколько по времени. Такая форма сохранения информации о вкладе, наверно, самая выгодная для участников, так как цена любой работы со временем растет, а любая валюта только девальвируется. И только информация о материальных (в том числе денежных) затратах будет сохраняться, с пересчетом на вес золота (в унциях, долях унции с точностью до рубля или копейки, или др. самой мелкой национальной денежной единицы). Об унции золота смотри в конце приложения подраздел справочная информация, а в нем пункт: «тройская унция». Часть вклада участника по его договоренности с соответствующими органами системы будет сохраняться на личном страховом счете участника. Ценность всех частей вклада будет со временем только возрастать.-

Автор будет ещё рекомендовать участникам КП принять на начальный период внедрения КП особый порядок вознаграждения (см. следом по тексту). А впрочем, всё это будут утверждать сами участники, консультируясь с экспертами, так как предлагаемый в этой презентации вариант это лишь видение автора.

\section{Особый порядок вознаграждения участникам КП на начальный период внедрения КП}

Введение особого порядка вознаграждения участникам КП вначале внедрения КП связано с тем без него начало внедрения КП может отложиться на долгие годы или, вообще, о КП и КСП забудут даже самые близкие люди. Так как для небогатых людей необходимо в первую очередь думать о материальном обеспечении себя и своей семьи (и с этим ничего не поделаешь, пока человек не разбогатеет, а это происходит, за исключением особых случаев или условий, не часто).

Предлагается (см. примечание в самом начале КПКП) следующая очередность выплат:

1) инвесторов БП и КП в целом (может быть другая очередность с письменного согласия инвестора); участникам КП (и БП) в особых случаях (например, в случае нехватки 
собственных средств участника на жизненно важное лечение или операцию и т.п.). Последнее должно быть оговорено в решении общего собрания, а в конкретных ситуациях определяться специального собрания или органа управления на основании соответствующего положения, утвержденного решения общего собрания участников КП (или БП);

2) участникам КП (и БП) в начальный период внедрения КП (и БП);

3) другим участникам КП (и БП) и т.д.

Могут быть и следующие очередности и условия, утвержденные решениями общего собрания участников КП (или БП). Собрания участников КП (или БП) могут быть заочными, а голосование дистанционным и электронным (интернет голосованием).

Вознаграждения выплачиваются из чистой прибыли КП (или БП) примерно так, как делаются выплаты акционерам дивидендов по акциям. Чистая прибыль определяется из прибыли за минусом затрат необходимых выплат. Кроме того из чистой прибыли до выплаты вознаграждений должны быть зарезервированы необходимые затраты на предстоящий период и необходимое развитие. Подробно порядок выплаты должен определяться участниками на основании рекомендаций экспертов (сначала, например, на основании заключений, рекомендаций экспертов от инвесторов, и др.).

Так как от начального периода внедрения КП (и от важнейших и важных вкладов участников) будет зависеть создание всей МС КСП, то общая сумма выплат участникам в начальный период внедрения КП будет распределена на все компании, их отделения и др. подразделения, приносящие чистую прибыль. Полное описание вкладов участников будет сохраняться в базе данных, и отдельно вклады в начальный период внедрения. Подробное описание вклада каждого участника будет составлять сам участник, а утверждать коллективный орган. Важность (и, соответственно, ценность) вклада каждого участника в начальный период внедрения КП будет проясняться (в сторону увеличения) по мере развития и расширения МС КСП, возможно, в течение длительного периода. И, соответственно, ещё более длительный период будут производиться выплаты и доплаты по вкладам участников по мере образования чистой прибыли в компаниях системы. Информация о денежных выплатах, цене оказанных услуг участникам будет сохраняться в базах данных системы с пересчетом на вес золота (в тройских унциях золота, с долями унции с точностью, соответствующей самой мелкой национальной денежной единицы). С учетом даты и времени перевода и поступления денежных средств на счет участника, даты и времени оказания услуг, их стоимости. Суммы выплат в золотом выражении участникам КП за вклад в начальный период внедрения КП будут постепенно доводиться (по мере образования чистой прибыли в компаниях системы) до лучших мировых стандартов (оплаты труда, интеллектуального или другого вклада).

\section{Направления развития КСП}

(резервы роста для молодых участников и возможности для участников КСП, а в будущем и не только для участников)

Ожидается, что первыми инвесторами КП будут магнаты, у подавляющего большинства из которых маячит проблема завещания и трастового управления их огромным бизнесом. Наследники разбалованы и демотивированы большими деньгами, и по признанию части самих же магнатов в подавляющем большинстве случаев приведут в упадок в конечном итоге бизнес, так как не имеют соответствующих способностей, опыта длительного самостоятельного управления бизнесом. А частные трастовые компании не вполне надежны даже на Западе. Планируется, что сначала консалтингово-трастовая компания (КТК) будет создаваться самим инвестором по договору с участниками БП. Ожидается, что часть участников БП, а может быть большинство, станет постоянными участниками будущей системы КСП. Это значит, что часть своего вознаграждения они сохранят в виде вклада на 
своем личном счете в страховом капитале в системе КСП (и будут страхователями, пользователями услуг системы КСП, а по взаимной договоренности и участниками в другой работе в системе КСП). Договор инвестора с участниками БП будет модифицироваться поэтапно с развитием системы КСП (и её готовности участвовать в управлении КТК), и трансформироваться в трехсторонний договор, когда это будет возможно и необходимо. С развитием международной системы (МС) КСП доли компаний КТК, созданные разными инвесторами, но принадлежащие МС КСП будут, по-видимому, как то объединяться, сначала фактически, а потом и формально. Так как их координатор и контролер будет один, а именно - МС КСП, а точнее - орган управления разными КТК, созданный МС КСП. Когда это объединение будет формализовано, оно и будет представлять собой международную КТК (MKTK) МС КСП. Подчеркнем, что в МС КСП будет одна общая основа - международная общественная организация, состоящая из национальных общественных организаций, где будет необходимость и будут условия для их создания (в основном в странах Запада). В большинстве других стран будут региональные системы КСП или какие-то неформальные общественные координационные объединения или центры, где будет необходимость и возможность их организации. Например, это может быть незарегистрированная общественная организация ВПГ, так как её регистрация пока не рентабельна. А работать она может примерно так, как описано далее по тексту во второй половине пункта: «Последовательность шагов по созданию общественной организации (OO) взаимопомощи граждан (ВПГ). Некоторые элементы организационной структуры ООВПГ (как они представляются автором)».

Кроме создания МКТК, перспективно, по мнению автора, создание международной информационно-посреднической системы по медицинскому обслуживанию (МИПСМО), естественно, платному и с ориентацией в первую очередь на богатых людей (из-за необходимости рентабельности её создания). МИПСМО важны такие качества КСП как: честность, объективность, не продастся (не будет сообщать неправду) ни за какие деньги (в отличие от многих представителей частного бизнеса, готовых рекламировать всё, что формально разрешено). Для МИПСМО объективность и честность это самые важные такие качества системы КСП. Тогда как международный (даже глобальный) характер МС КСП должен обеспечить эффективность, а для развитого состояния этой системы даже высокую рентабельность. Со временем потребность в МИПСМО будет только возрастать, так как наиболее способные, а тем более талантливые, врачи, ученые, инженеры из большинства стран мира уезжают, и будут продолжать в большинстве своем уезжать в Западные страны с наиболее высоким уровнем жизни и лучшими условиями для работы. А все сферы жизни (особенно медицина и смежные с ней научные области различных наук) будут становиться всё технологичнее, требовать более высокого уровня образования, условий, финансирования. В связи с этим в большинстве стран мира вместе с медициной, наукой, будет «проседать» и образование (особенно высшее, так как оно напрямую связано с наукой) по сравнению с вышеуказанными Западными странами. А мировой «средний класс», с прослойкой населения Земли, обладающей доходами на уровне «среднего класса» и выше будет всё больше (точно не меньше) ценить лучшие медицинские центры, интересоваться и использовать их возможности. Одновременно эти центры и их возможности будут продолжать расти. А МИПСМО будет постоянно мониторить возможности этих центров, и предлагать населению Земли, особенно, обладающему доходами на уровне «среднего класса» и выше, качественные (в том числе объективные и надежные) информационно-посреднические услуги. А в развитом состоянии МИПСМО будет предлагать улучшения качества обслуживания во всех областях, которые она сможет обеспечить (кроме медицины), возможностей рекомендуемых лучших медицинских центров. И в ещё более дальней перспективе МИПСМО, используя возможности всей МС КСП, возможно, будет создавать по договоренности с этими медицинскими центрами совместные отделения и филиалы в других странах, где это можно сделать рентабельно, а самое главное без потери качества. 
МИПСМО при этом будет брать на себя решение всех вопросов (в том числе обеспечения всем необходимым), кроме лечения и проведения операций и того, что она не сможет решить лучше.

Перспективно, по мнению автора, создание в МС КСП международной общественной финансовой системы (МОФС) обеспечивающей надежное и долговременное хранение финансовых средств (валюты, драг металлов и др.). Предполагается, МОФС будет включать в качестве подсистем: сначала, международный общественный банк (МОБ), а потом международную общественную страховую компанию (МОСК) и, наверное, международную общественную пенсионную систему (МОПС). При этом центральные офисы этой системы будут находиться в Западных странах с наиболее благоприятными для такой системы условиями, обеспечивающими надежное и сколь угодно долговременное сохранение финансовых средств. А в странах с неустойчивыми режимами и отсутствием независимой судебной системы будут находиться филиалы с ограниченным набором функций: оформлением договоров, внесением и переводом средств на ПК, счета в других банках, платежи и др., чтобы при любых обстоятельствах в этих странах клиенты не потеряли свои средства. Возможно, МОФС будет иметь свою криптовалюту.

Другие возможные направления развития МСКСП. Возможно, создание и развитие (может быть, под эгидой ЮНЕСКО) международной открытой операционной системы (и пакета всех основных прикладных программ) для образования и науки. Операционной системы и пакета, которые будут бесплатны для малообеспеченных граждан. Представляется рациональной идея создания международной системы здорового питания в первую очередь для детей в школах, ВУЗах и в др. организациях (с договоренностями с правительствами пожелавших стран о локализации этих систем в конкретных странах). Возможно, создание международной информационно-посреднической системы сертифицированных лекарств, создание международной информационно-потребительской системы качественных товаров и услуг, и др. систем.

\section{С чего начинать работу по созданию КСП}

Каждый участник КП заинтересован в привлечении новых участников им. Так как любому участнику любого проекта КП будет важно, чтобы его нематериальный вклад был весомее и чтобы он быстрее мог воспользоваться желаемыми услугами от системы КСП, необходимо, чтобы как можно скорее заработали соответствующие проекты и части системы КСП. А сначала необходимо, чтобы заработал бизнес проект (БП или проекты), финансово подпитывающие внедрение и развитие КП. Т.е. необходимо найти инвесторов, которые возьмутся за финансирование БП. Весьма маловероятно, чтобы сам первоначальный участник вышел на такого инвестора (даже регионального), и чтобы он смог сам инвестора заинтересовать проектом. Но в этом как раз и есть одно из преимуществ коллективного предпринимательства, что можно использовать социальные связи многих людей, и что особенно важно в начальный период реализации проекта.

Автор проекта или один из первых участников, который, скорее всего, будет участвовать в работе над презентацией КП, начнет привлекать участвовать в КП своих знакомых, которых сочтет теми, кто, по его мнению, может заинтересоваться КП. А также выходить на других людей (см. п.1), которые могут быть потенциальными участниками. И так же станут поступать и некоторые из тех, к кому он будет обращаться. В результате будет образовываться одна «цепочка» участников. Если один или два участника «цепочки» заинтересуют КП не одного, а двух своих знакомых, то у этой «цепочки» возникнут «ответвления», которые в будущем, возможно, фактически приведут к образованию нескольких «цепочек» участников КП. В результате, возможно, одна (а может быть не одна) цепочка выведет на заинтересовавшегося реализацией КП инвестора. В результате так начнется реализация КП. 
Подробнее о продолжении работы по созданию системы КСП см. далее в Приложении в пункте: «Дополнительно о необходимой работе по созданию общественной организации взаимопомощи граждан и, вообще, что обязательно нужно сделать в начальный период создания КСП».

\section{Приложение (пояснения, дополнения) к КПКП}

Некоторые наиболее важные замечания о первоочередных шагах внедрения КП

Не стоит, наверно, думать о реализации сразу в Томске и в других региональных центрах информационно-посреднической системы по медицинскому обслуживанию (ИПСМО). Хотя, в Томске, наверно, лучше условия для этого, реализация одного такого проекта, скорее всего, просто будет нерентабельна. Реален, возможно, какой-то гибридный подход. Поясним, что имеется в виду. В Томске, или в каком-то региональном центре можно поискать выход на регионального инвестора, заинтересованного в создании надежной компании трастового управления и консалтинга (и, в первую очередь, надежной для самого этого регионального инвестора), и, обязательно, поддерживаемого региональными властями. Возможно, что региональный инвестор заинтересуется и (или) направлением создания международной ИПСМО с организацией выхода на более крупного инвестора(ов), которому(ым) будет под силу реализация такого крупного проекта в связке с проектом создания консалтинговотрастовой компании (KTK) и международной (KTK, т.е. МКТК) международной системы (MC) КСП. При этом региональный инвестор будет обязательно иметь в этих проектах свою долю, пропорциональную его вкладу. Тогда в Томске, или в соответствующем региональном центре, возможно, будет создание регионального центра в том варианте (и, соответственно, размерах), который будет рентабелен. Тем не менее, начало внедрения КП с создания одной только компании КTK, по мнению автора, скорее всего, более вероятно.

И ещё: участникам КП (особенно, небогатым) необходимо (в целях информационной взаимопомощи) совместно собирать информацию о лучших врачах в региональных центрах и других городах, и о том, как к ним можно попасть (независимо от продвижения работы по созданию ИПСМО и других КСП систем). А также о том, как лучше поступать в других (житейски важных и нередко возникающих) ситуациях, и, особенно, в экстренных случаях.

\section{О важности общественной организации (OO) взаимопомощи граждан (ВПГ) в концепции КСП и КП}

В КП ОО ВПГ, учреждающая хозяйственную организацию в организационно-правовой форме юридического лица общества с ограниченной ответственностью (OOO), - важнейшая часть структуры КП, которая позволяет реализовать все возможности, заложенные в КП, и достичь выполнения целей концепции КСП. Перечислим и кратко опишем их.

А) Постоянная пополняемость (и рост) и быстрая изменяемость структуры системы КСП (за счет возможностей ОО ВПГ и связки ООВПГ=॰ООО), обеспечивается притоком новых участников системы КСП (СКСП). Отсюда неограниченное время развития (другими словами и, образно говоря, время жизни = вечности).

С) Отбор нравственно лучших (проще говоря, самых добросовестных), а среди них лучших по необходимым профессиональным качествам, всех работников (и, особенно, для работы на ответственных, координирующих, руководящих и контролирующих должностях), обеспечивает надежность и качество не только отдельных, а всех услуг, предоставляемых 
СКСП как участникам, так и другим гражданам и организациям. Кроме того в развитом состоянии будет осуществляться по заключению экспертов необходимый мониторинг работы части работников, и определенных участков работы систем КСП. Будет проводиться также по заключению экспертов необходимый внутренний контроль и внутренний аудит, а в необходимых случаях и экстренный внутренний контроль, и внутренний аудит работы отдельного участка и отдельного работника.

d) Международный характер международной системы (MC) КСП, глобальность в развитом состоянии, а в более отдаленном будущем - включенность всех стран и регионов. За счет координации работы всех национальных и региональных общественных организаций МС КСП международной организацией (MO) МС КСП, работы международных компаний (MK), входящих в МС КСП, будет обеспечиваться взаимовыгодный обмен услугами, многократный рост эффективности и прибыльности МК, как национальных и региональных систем КСП, так и всей МС КСП. Внутри МС КСП за счет работы МС КСП будет обеспечиваться развитие без внутренней конкуренции внутри МК МС КСП и совершенная конкуренция МК МС КСП с другими компаниями на международном рынке.

Отсюда возникают эксклюзивные (эмерджентные) качества и преимущества всех систем КСП.

В некоторых странах Запада связку ОО ВПГ, учреждающая ООО, придется заменять другой конструкцией в зависимости от законодательства. Но это неважно, главное, чтобы сохранялись те же самые основные возможности, которые перечислены и описаны выше.

\section{О значении СКСП и МС КСП для фактически одиноких людей и для тех, кому маячит такое одиночество в будущем}

О важности СКСП и МС КСП для фактически одиноких людей и для тех, кому маячит такое одиночество в будущем (что тоже может случиться у большинства людей).

СКСП и МС КСП в развитом состоянии сможет оказывать участникам и просто клиентам достаточно продолжительную (не разовую) помощь, даже не связанную с уходом, а просто информационно-посредническую, например, в решении каких-либо вопросов при жизни, и выполнит необходимые действия после смерти. В частности, СКСП выполнит действия связанные с длительным исполнением завещания. В этом случае ООО может быть наследником, а учредившая его ОО ВПГ сможет быть не формальным, а фактическим душеприказчиком (надежным контролером) исполнения завещания этим наследником (т.е. ООО). Хотя участник и просто клиент заключит именно с ООО (как наследником) наследственный договор. Наследственный договор может также содержать условие о душеприказчике и возлагать на участвующих в наследственном договоре лиц, которые могут призываться к наследованию, обязанность совершить какие-либо не противоречащие закону действия имущественного или неимущественного характера.... (См.: ГК РФ Статья 1140.1. Наследственный договор (введена Федеральным законом от 19.07.2018 N 217-Ф3).

Для богатых клиентов даже возможно организовать уход за больным и (или) престарелым родственником. Причем клиент (и (или) ООО как пожелает клиент) заключит соответствующий договор с платным домом (пансионатом и т.п.) или с платной организацией, осуществляющей уход за больным и (или) престарелым клиентом или его родственником на дому.

Мысленный (т.е. умозрительный) прогноз и анализ показывает, что нет хорошего по надежности решения даже в регионах (в незападных странах) без региональной подобной ОО. Так как невозможно одинокому завещателю (без близких и надежных родственников или других людей существенно моложе его) завещать кому то одному или немногим наследникам. Составлять же завещание с большим числом физических лиц дорого и не реально. А в западных странах проблем с регистрацией и надежной работой ООВПГ (или подобной по возможностям структуры связке ОО ВПГ, учреждающая ООО, которая может 
быть заменена другой конструкцией в зависимости от законодательства) не будет (это аксиома, так как нет тех причин, по которым затруднена и ненадежна работа вышеуказанной связки в незападных странах). Благо, что в незападных странах богатые и те, кто у власти (и при власти) в регионах будут заинтересованы в работе КП КСП (тем более совершенно без политики). Поэтому они смогут создаваться и успешно работать и там (правда, большие суммы денег в банках в незападных странах хранить всё же не желательно).

Последовательность шагов по созданию общественной организации (OO) взаимопомощи граждан (ВПГ). Некоторые элементы организационной структуры ООВПГ

(как они представляются автором)

Сначала, наверно, должно быть накопление участников будущей ОО, ознакомление их с КП. Опрос участников и сбор их контактных адресов, выяснение, чем бы они хотели заниматься, и как будут участвовать эпизодически или постоянно (и сколько по времени). Те участники, которые будут готовы работать более или менее постоянно, делятся на группы, намечают и обсуждают вопросы, которые будут прорабатывать, знакомятся. Через какой-то период начальной работы (по мере увеличения количества активных участников до определенного уровня) лучших и наиболее активных участников делегируют от групп и выбирают на общем собрании кандидатами в члены организации. Предполагается, что члены организации будут обладать не совещательным, как участники, а решающим голосом. Дальше примерно также: кандидаты работают и знакомятся вместе и по группам, обсуждают устав и положения будущей общественной организации (OO). ОО (приняв устав и положения) может довольно долго (даже неограниченно по времени) работать без регистрации и, не занимаясь финансово-хозяйственной деятельностью. Тогда как финансовохозяйственная деятельность требует открытие счета в банке и, соответственно, регистрации и отчетности в налоговых органах.

Кандидаты в члены и участники организации работают по информированию и привлечением новых участников. Затем кандидаты в члены с постоянно работающими участниками избирают на общем собрании членов организации, и, возможно, новых кандидатов в члены организации. Члены организации работают над первоначальной структурой организации, включающей, возможно, координационные, законодательные (на уровне организации), контролирующие, и исполнительные органы. Деятельность этих органов будет регламентироваться отдельными положениями, принятыми, как и устав, общим собранием ОО. Однако в отличие от устава их не нужно регистрировать. Все эти органы будут организовываться (и приниматься положения по ним) по мере необходимости, а главное - их создание и работа должна экономически оправдываться, т.е. окупаться. Должна экономически окупаться регистрация и работа полноценных ОО, ООО и связки ООВПГ=॰ООО. Что в начальный период реализации КП будет достижимо, скорее всего, только для московского мегаполиса.

По мнению автора, в самом начале создания различных органов организации должна создаваться этическая комиссия организации (нравственный «отдел кадров» организации). Она должна собирать автобиографии членов организации, создавать и вести базу данных, содержащую нравственные и профессиональные досье на членов организации. В начальный период создания организации должны почаще проводиться выборы членов и органов организации, чтобы отбирать самых добросовестных и, при этом, самых профессиональных, а также работящих (т.е. трудолюбивых) участников организации. Да и в следующие периоды перевыборы должны проводиться регулярно и не редко. И, при этом, должны быть 
ограничения на суммарный срок работы на руководящей должности (а дальше только в качестве ВРИО пока нет другой кандидатуры, не уступающей по вышеуказанным качествам). Кроме того, у работающих на руководящих и материально ответственных должностях должны быть не оплаченные вклады, в пределах сумм которых они и смогут принимать в случае крайней необходимости единоличные решения. А решения на большие суммы и в обычной ситуации должны приниматься коллегиально, и их исполнение должно контролироваться представителем контрольной комиссии. А состав контрольной комиссии должен определяться и утверждаться наблюдательным советом ООО совместно с этической комиссией ОО.

Как указывалось выше, экономически окупаться регистрация и работа полноценных ОО, ООО и связки ООВПГ=॰ООО в начальный период реализации КП будет, скорее всего, только для московского мегаполиса. Пока регистрация и работа связки ООВПГ $\triangleright$ ООО в региональном центре не будет рентабельна, представляется возможной следующая схема работы не сформировавшейся достаточно ООВПГ. Допустим, сформировалось некоторое сообщество фактически одиноких граждан, желающих создать ООВПГ. А дальше ему необходимо действовать примерно по такой схеме, как уже описано в начале пункта. Избрать, когда это сообщество будет готово, членов и принять устав ООВПГ без намерения его (в этой первой редакции) и в ближайшее время регистрировать. При этом в уставе прописать только общие моменты и то, что обязательно необходимо. Подробности же прописывать в отдельных положениях. А дальше устав, пока не потребуется регистрация, можно сколько угодно раз дополнять, совершенствовать, и положения тоже (они, тем более, не требуют регистрации). Далее же, когда потребуется оформлять наследственный договор с организацией, необходимо договариваться с московской ООВПГ о проведении всех обязательных юридических действий через московскую связку ООВПГ=॰ООО. При этом все свои затраты московское ООО, учрежденное московской ООВПГ (так, чтобы работа московской связки с клиентом была рентабельна), будет компенсировать по договору с клиентом. Возможно, московская ООВПГ заключит не финансовый договор с региональной (или городской) ООВПГ о совместной деятельности. А соответствующее московское ООО заключит агентские (или иные) соглашения с теми людьми, которых порекомендует региональная (или городская) ООВПГ. Не финансовый договор с городской ООВПГ о совместной деятельности будет заключаться, если не московская ООВПГ будет организована в не региональном центре. Когда же клиентов в этом региональном центре (или городе) станет достаточно много для рентабельной работы филиала московского ООО, то такой филиал может быть организован. При этом работа филиала будет контролироваться наблюдательным советом совместно с региональной (или городской) ООВПГ. При этом оказание необходимых услуг клиенту из поселка или деревни может быть организовано местным активом соответствующей региональной (или городской) ООВПГ по договоренности с местной администрацией, так как она, скорее всего, тоже будет заинтересована в этом. Дополнительно см. следующий пункт.

Дополнительно о необходимой работе по созданию общественной организации взаимопомощи граждан и, вообе, что обязательно нужно сделать в начальный период создания КСП

Описанный выше вариант создания общественной организации (OO) взаимопомощи граждан (ВПГ) не подразумевает соучастия инвестора и участников БП. Он будет реализовываться там, где мало первоначальных и потенциальных участников и невозможен или не будет найден выход на инвестора БП. Однако такой вариант создания ОО маловероятен или может затянуться на долгие годы начальный период создания КСП. К счастью, инвесторы вышеупомянутых (или, вообще, возможных) в КСП бизнес-проектов больше всех заинтересованы в создании полноценной ОО ВПГ (а в перспективе даже 
международной ОО и международной системы (MC) КСП). Так как без неё никакой подобный БП в принципе не реализуем. Инвесторы таких БП больше всего вынуждены при их реализации соблюдать данные обязательства, и кровно заинтересованы, в том, чтобы в члены, связанных с реализацией их БП, ОО ВПГ отбирались только добросовестные участники. Так как такие организации не могут быть частично порядочными, иначе инвесторы просто потеряют вложенные средства. Поэтому в таких ОО с большим количеством активных участников обязательно будут третейские суды, будет он и в международной организации МС КСП (может быть с разными коллегиями в зависимости от участников и тематики споров). Члены коллегий третейских судов должны быть компетентны по теме спора, а так же, как члены организаций, проходить строгий нравственный отбор. Споры могут возникать между участником (и группой участников) БП и инвестором БП по оценке вклада, а также при заключении каких-то соглашений между ними. Однако третейские суды, скорее всего, начнут создаваться не в начальный период создания КСП. Поэтому вернёмся к заявленной в названии теме пункта.

После того как описано выше в пункте: «С чего начинать работу по созданию КСП» одна из образовавшихся нескольких «цепочек» участников КП выведет на заинтересовавшегося реализацией КП инвестора, собственно и начнется реализация КП.

Для подготовки контроля топ-менеджмента любой компании в регионе будет достаточно и незарегистрированной работающей ОО ВПГ и небольшой начинающейся организационно ООО, контролируемой ОО. Но чтобы эта связка была надежной и самоокупаемой необходимо увеличение численности активных участников ОО необходимо создавать такую же связку в Москве. Там она быстрее будет создана, наберет достаточное количество активных участников, и у неё будет крупный инвестор (а, может быть, и не один даже в начальный период). И чем больше будет инвесторов, тем лучше. Может образоваться альянс инвесторов, и они решат, как будет дальше развиваться общественная КТК (или компания по другому направлению). Могут установиться связи общественной компании (OK) с лучшими крупными западными частными компаниями по соответствующему направлению, согласными сотрудничать с ОК и между собой при посредничестве ОК. И это неформальная группа частных компаний будет координировать свою работу при посредничестве ОК. И, соответственно, будет распределяться предварительными соглашениями прибыль от совместной работы. Компенсация затрат на экспертные заключения и (наверно, большая) часть прибыли за эту работу будет перечисляться частным компаниям пропорционально их вкладу. А то, что останется ОК, это оплата работы связки ОО ВПГ с ОК за координацию и за контроль, если он будет оговорен заказчиком, работы менеджмента компаний заказчика, в том числе этический контроль. Кроме такой работы, ОК необходимо регулярно анализировать ситуацию по услугам, которые не оказывают (или что-то делают не достаточно) частные компании. И организовывать то, что ОК может сделать дополнительно или лучше (при условии рентабельности этой работы для ОК).

С развитием международной системы (МС) КСП и международных общественных компаний (MOK) МС КСП, вероятно, будет возрастать (когда это будет рентабельно) и число отдельных национальных общественных компаний, особенно в западных странах. Скорее всего, (также, когда это будет рентабельно) МС КСП организует и координационную международную общественную компанию, которая будет не только координировать, но и, возможно, контролировать в каких-то аспектах работу МОК. Но это всё, почти наверняка, будет не в ближайшем будущем, а когда МС КСП будет уже в достаточно развитом состоянии. Поэтому вернёмся к начальному периоду создания КСП.

Контроль, в том числе этический контроль, если он будет оговорен заказчиком, работы менеджмента компаний заказчика связкой ООВПГ=॰ООО будет возможен и в начальный период создания КСП. Более того, именно он и будет составлять основу прибыли системы КСП (особенно, в начальные периоды создания и развития КСП). А чтобы такой контроль осуществлять, необходима развитая ООВПГ, и чем больше в ней будет добросовестных и 
активных членов, тем лучше (особенно готовых заниматься контрольной деятельностью в ООО и самосовершенствоваться в этой области). А для того, чтобы привлекать новых членов в ОО необходимо создать сайт (если возможно, то с финансовой помощью инвестора) или находить существующие сайты, организаторы которых готовы поместить информацию о КП КСП. А уже имеющимся активным участникам КП выходить через своих знакомых на новых потенциальных участников КП, обращаться в различные организации, которые, возможно, каким-либо образом захотят участвовать в КП. И чем больше участников будет заниматься такой работой, тем больше будет новых «цепочек» участников, выходящих на новых участников и инвесторов (в том числе иностранных) и на новые возможности внедрения КП.

\section{Краткая история работы над проектом}

Представленный проект - это результат работы над идеей развития коллективного предпринимательства начиная с весны 1999г. Развития такого предпринимательства сначала на основе кооперации в области некоторых инноваций разработчиков из разных университетов, и с конца 2001г., можно сказать, началась работа над этим проектом.

Это версия КП, которая разрабатывается автором с весны 2017г. на основе долгого анализа более ранних вариантов. Версия 2012 $\div 2013$ гг. была, как вскоре стало ясно слишком оптимистической, реализуемой лишь теоретически, в идеалистических условиях, без учёта уже сложившихся и складывающихся в 2019 г. жизненных реалий. Не говоря уже о более ранних вариантах с 2006г., а тем более о первых попытках, предпринимаемых с начала 2002г. С весны 2002г до начала лета 2006 г. автором создавались основы концепции КСП, изложенной в первой неопубликованной брошюре 2006 г. (концепции коллективного предпринимательства (КСП), которое называлось автором тогда общественным инновационным предпринимательством (ОИП)). Эта концепция (КСП) является теоретической основой КП. Тем не менее, все полезное, что было в предыдущей версии и этих ранних вариантах, попытках, автор постарался учесть в представленной версии КП.

\section{Будущее МС КСП}

МС КСП, по мнению автора, - в будущем (к сожалению, наверно, очень далеком для большинства стран) будет основой сначала почти всей социальной сферы, а потом и большей части всей мировой экономики (особенно, в тех областях, где важны надежность и качество). Да и управление в государственных структурах будет во многом аналогичным, особенно, что касается нравственного отбора и продвижения кадров на всех руководящих и ответственных должностях, контроль и оценка работы (и соответственно вознаграждения, зарплаты) всех работников без исключения будут осуществляться аналогично. Частные предприятия будут в тех сферах, где необходим экономический риск, важны талант и способности, особенно в инновационных разработках. Контроль частного сектора будут осуществлять общественные структуры, оплата их работы производится государством, которое в свою очередь будет контролироваться общественными структурами и полностью управляться обществом. Управляться обществом, как указано выше в том, что касается отбора и продвижения кадров, контроля и оценки работы (и соответственно вознаграждения, зарплаты) всех руководящих и ответственных работников общественными структурами.

\section{Справочная информация}




\section{Общепринятые сокращения}

Общепринятые сокращения сделаны согласно смотри (см.): Основные общепринятые графические сокращения: как правильно их писать. Список сокращений процитирован по приложению 1 к «Русскому орфографическому словарю» под редакцией В. В. Лопатина, О. Е. Ивановой. Издание 4-е, исправленное и дополненное, М., 2013. https://popravilam.com/blog/sokrashcheniya-osnovnye.html

\section{Краткая справка по наследованию}

Завещатель не ограничен в количестве составляемых им завещаний, он может распорядиться имуществом или какой-либо его частью, составив одно или несколько завещаний. В завещаниях могут содержаться распоряжения в отношении разных наследников, в отношении разного имущества.

Завещание может содержать в себе несколько завещательных распоряжений.

Завещатель может назначить в завещательном распоряжении душеприказчиков.

Наследодатель и завещатель. В чем разница? См.:

https://zakonoved.expert/terminologiya/kto-takoj-nasledodatel.html

Наследодатель вправе заключить с любым из лиц, которые могут призываться к наследованию (статья 1116), договор, условия которого определяют круг наследников и порядок перехода прав на имущество наследодателя после его смерти к пережившим наследодателя сторонам договора или к пережившим третьим лицам, которые могут призываться к наследованию (наследственный договор). Наследственный договор может также содержать условие о душеприказчике и возлагать на участвующих в наследственном договоре лиц, которые могут призываться к наследованию, обязанность совершить какиелибо не противоречащие закону действия имущественного или неимущественного характера.... См.: ГК РФ Статья 1140.1. Наследственный договор (введена Федеральным законом от 19.07.2018 N 217-Ф3)

\section{Тройская унция}

Тро́йская у́нция - единица измерения массы, равная 31,1034768 грамма. Название тройская унция произошло от французского города Труа (фр. Troyes), находящегося на севере Франции, на реке Сена, в провинции Шампань.

Международное обозначение тройской унции золота, серебра, платины и палладия соответственно XAU, XAG, XPT, XPD.

Официальная мировая цена на золото во всем мире выражается в долларах США за одну тройскую унцию. В наше время, цена за тройскую унцию золота устанавливается посредством Лондонского фиксинга. Он проводится представителями пяти крупнейших банков - игроков рынка драгоценных металлов. Установка фиксированной цены на унцию золота производится два раза в день. Это происходит в 10:30 и в 15:00 по лондонскому времени или в 13:30 и 18:00 по московскому времени.

\section{Презентация комплексного проекта}


Презентация КП КСП

кооперативного социального предпринимательства 